\title{
Optimization of PVA-Arabic Gum-Honey-based Electrospun Nanofibers as Candidate Carrier for Peptide and Protein Delivery
}

\author{
Ningsih Rezeki ${ }^{1}$, Khairurrijal ${ }^{2}$, Silvia Surini ${ }^{1 *}$ \\ ${ }^{1}$ Faculty of Pharmacy, Universitas Indonesia, Depok, Indonesia \\ ${ }^{2}$ Department of Physics, Faculty of Mathematics and Natural Sciences, Institut Teknologi Bandung, Bandung, Indonesia
}

\begin{abstract}
Nanofibers dressing exhibit several advantageous characteristics for accelerating wound healing, such as its similar structure to the extracellular matrix (ECM), high surface area/volume ratio, high porosity and high loading capacity of drug. The nanofibers dressing which were prepared by the electrospinning technique using combination of synthetic and natural polymer excipients capable of fulfilling the ideal wound dressing criteria. This study aimed to develop nanofibers dressing prepared from polyvinyl alcohol (PVA), Arabic gum (GA) and honey by electrospinning method. This study focused on the effect of electrospinning parameters and the morphology of electrospun nanofibers of the blended solutions made from PVA $(9 \% \mathrm{w} / \mathrm{v})-\mathrm{GA}(1 \% \mathrm{w} / \mathrm{v})$ and honey (at varied concentrations of $0 ; 1 ; 3 \% \mathrm{w} / \mathrm{v})$ with or without Triton X-100 $(0.05 \% \mathrm{v} / \mathrm{v})$. The effect of varied process parameters such as voltage and flow rate in electrospinning was also investigated. The blended solutions with the various concentration of honey at $0 ; 1 ; 3 \% \mathrm{w} / \mathrm{v}$ and Triton $\mathrm{X}-100$ were named as FAt, FBt, and FCt, respectively, while the blended solutions without Triton X-100, were named as FA, FB, and FC. The optimum electrospining parameter were $18 \mathrm{KV}$ and $5 \mu \mathrm{l} /$ minute for FAt, FBt, and FCt; and $20 \mathrm{KV}$ and $10 \mu \mathrm{l} /$ minute for FA, FB, and FC. Electrospun nanofibers of FAt, FBt, FCt showed smoother and more uniform fibers in comparison to the nanofibers FA, FB, and FC. The average nanofibers diameter of FAt, FBt, FCt were $244 \pm 45 ; 266 \pm 45$; $283 \pm 57 \mathrm{~nm}$, respectively, while the average nanofibers diameter of FA, FB, FC was $406 \pm 140,457 \pm 168$, $594 \pm 204 \mathrm{~nm}$, respectively. Higher concentration of honey increased the diameters of nanofibers. The average nanofibers diameter of FAt, FBt, and FCt were within nanoscale in range of the ECM (50-500 $\mathrm{nm}$ ), which were suitable for accelerating wound healing. Therefore, this study indicated that PVA-GAhoney nanofibers dressing is suitable to be further developed as carrier for growth factors.
\end{abstract}

Keywords: arabic gum; electrospinning; honey; nanofibers; polyvinyl alcohol

*corresponding author

Email:silvia@farmasi.ui.ac.id

\section{INTRODUCTION}

Wound healing process is a very complex process consisting haemostasis, inflammation, proliferation and remodeling phases (Orue et al., 2017). All phases of the wound healing process are controlled by active endogenous compounds, one of them is growth factors. Growth factors are biologically active polypeptides that play a crucial role in regulating wound healing process in which involved in cell proliferation, differentiation and migration (Gainza et al., 2015). Currently, treatment with growth factors require high doses and is administered over long periods of time. The conventional formula cannot prevent the rapid degradation rate of growth factors (Park et al., 2017). Therefore many research have been performed to develop delivery system for growth factors. Among them is by loading growth factor intonanofibers wound dressing formula by electrospinning to protect the growth factor from invivo degradation, to improve its stability and control its release (Orue et al., 2017).

Nowadays the fabrication of wound dressing formula has attained higher criteria based on the principle of creating and maintaining a moist wound environment, in which accelerating wound healing, skin regeneration, oxygen exchange, and inhibiting bacterial infection (Felgueiras et al., 2017). Electrospun nanofibers considerable promising as wound dressing. It has several structural advantages for accelerating wound healing process due to their physical structure which mimics to the threedimensional structure of natural extracellular matrix as well as their high ratio of surface area to volume and a high interconnected porosity (Zhang et al., 2017). Besides that, the nanoscale size of the fibers causes the nanofibers dressing able to function as a barrier for preventing bacterial contamination (Asli et al., 2016). In addition, nanofibers dressing also demonstrated a high drug-loading capacity and additionally, they provide an tremendous protection from environmental harms (Orue et al., 2017).

The selection of the suitable material for nanofibers dressing is a challenge. Various synthetic polymers, natural polymers and the mixtures of both have been successfully fabricated for the development of nanofibers dressing. Synthetic polymers provide many advantages as compared to natural polymers, due to its degradability and its ability to produce consistent batch-to-batch 
characteristics including mechanical properties (elastic and rigid). Their slow rate of can promote controlled release of the loaded drugs. Synthetic polymers are also more convenient to spin because they are compatible with various solvents. However, synthetic polymer also have limitations, such as low biocompatibility and the existence of solvent residues. Low biocompatibility will result in slower cell attachment and proliferation rates as compared to the natural polymers (Asli et al., 2017).

Natural polymers are of great interest to researchers as compared to synthetic polymers due to its biocompatibility, cheaper price and non-toxic characteristic. However, natural polymers showed less favorable mechanical properties and their degradation rates are relatively rapid, which limit their use to fabricate nanofibrous wound dressing, unless they are combined with synthetic polymer (Orue et al., 2017; Zhang et al., 2017). One of natural polymers is arabic gum (GA). Previous studies reported that arabic gum solution could form a smooth and uniform nanofiber by mixing the solution with synthetic polymers such as polyvinyl alcohol (PVA) (Padil et al., 2016). In addition, Bhatnagar et al (2013) recently also reported that arabic gum has potential as wound dressing due to its antibacterialand hemostatic activity.

Nanofibrous dressing from combination of both synthetic and natural polymer offer characteristic which can meet the ideal wound dressing criteria. To date, loading growth factors into the matrix of polyvinyl alcohol (PVA)-arabic gum (GA) has not been studied yet. PVA is a synthetic polymer that is easily soluble in water, biocompatible, electrospinnable and possess strong mechanical properties (Zhang et al., 2017). PVA can also be used for sensitive macromolecules such as proteins because itits electrospinning process does not require organic solvents that have the potential to denature proteins (Asli et al., 2016). Honey was also added into the composite polymer to improve the stability of growth factors during the electrospinning process. (Wong et al., 2013). In addition, honey can improve the wound healing process because of its antibacterial, anti-inflammatory and antioxidants activity (Oryan et al., 2016).

The selection of the water instead of organic solvents give challenge in electrospinning because of its high surface tension. Therefore, Triton X-100 was added as surfactant to the formulation to reduce its surface tension and to increase spinnability of electrospinning blended solution. Additionally, during the electrospinning process, all parameters such as solution properties (viscosity, surface tension, and conductivity), process parameters (flow rate, tension, needle size, distance between needle and collector) and ambient parameters (temperature and humidity) were controlled. This present study was carried out to optimize fabrication of nanofibers dressing using varied composition of blended solution and process parameters such as voltage and flow rate, and to evaluate the morphology of obtained nanofibers dressing.

\section{METHODS}

\section{Materials}

Gum arabic spray-dried (Merck, Germany), PVA $(\mathrm{BM}=145,000$ hydrolysis degrees 98.0-98.8 $\mathrm{mol} \%)$ (Merck, Germany), deionized water, buffer phosphate (PBS), Indonesian honey, and Triton X-100 (SigmaGermany).

\section{Instruments}

The instruments used in this study were Electrospinning 601 (Nachriebe, Indonesia), Analytical scales (Sartorius, Germany), Rotational viscometer (Meyer,USA), Conductometer (Mettler, USA), Tensiometer (Du noy, Germany), Scanning electron microscopy (Hitachi, JEOL JSM-6510LV, Japan), Magnetic stirrer, syringes and glassware (Pyrex).

\section{Preparation of PVA-GA-Honey-based Nanofibers Dressing without Triton X-100}

The electrospinning solutions were prepared based on Formula FA, FB, FC and FD (Table 1) by dissolving 0.9 gr PVA with hot water (temperature $\pm 80{ }^{\circ} \mathrm{C}$ ) and stirring for 2 hours using a magnetic stirrer., GA (0, 1 gr) was added to PVA solution, and mixed until homogen. Varied concentrations $(0 ; 1 ; 3$; and $5 \% \mathrm{w} / \mathrm{v})$ of honey was then added to the solution, and deionized water were added until the total volume of $10 \mathrm{ml}$.

\section{Preparation of PVA-GA-Honey-based Nanofibers Dressing with Triton X-100}

The electrospinning solutions were prepared based on Formula FAt, FBt, and FCt (Table 2) by dissolving 0.9 gr PVA with hot water (temperature $\pm 80{ }^{\circ} \mathrm{C} \mathrm{f}$ ) and stirring for 2 hours using a magnetic stirrer. GA (0.1 g) was added to PVA solution, and mixed until homogen. Varied concentrations $(0 ; 1$; and $3 \% \mathrm{w} / \mathrm{v})$ of honey and Triton X-100 $(0.05 \% \mathrm{v} / \mathrm{v})$ were then added to the solutions. Finally, deionized water were added until the total volume of $10 \mathrm{ml}$.

\section{Electrospinning procedure}

PVA-GA-Honey solutions were loadedin $5 \mathrm{ml}$ syringe with a diameter of $0.7 \mathrm{~mm}$. Afterwards, the nanofibers dressing were fabricated with the condition of electrospinning as follows (see Figure 1): the electrical voltage used was $16-20 \mathrm{kV}$, the flow rate of the solution was $5-10 \mu \mathrm{l} /$ minute, the distance between the needle tip and collector was $18 \mathrm{~cm}$ and the collector rotation speed was $300 \mathrm{rpm}$. The electrospinning process was carried 
Table 1. Formula and physical caracteristic of PVA-GA-honey-based nanofibers dressing

\begin{tabular}{lllllll}
\hline Formula & $\begin{array}{l}\text { PVA } \\
(\% \mathbf{\%} / \mathbf{v})\end{array}$ & $\begin{array}{l}\text { GA } \\
(\mathbf{\%} \text { w/v) }\end{array}$ & $\begin{array}{l}\text { Honey } \\
(\mathbf{\%} \text { w/v) }\end{array}$ & $\begin{array}{l}\text { Viscosity } \\
(\mathbf{m P a . s})\end{array}$ & $\begin{array}{l}\text { Surface tension } \\
(\mathbf{d y n e} / \mathbf{c m})\end{array}$ & $\begin{array}{l}\text { Conductivity } \\
(\boldsymbol{\mu S} / \mathbf{c m})\end{array}$ \\
\hline FA & 9 & 1 & 0 & $573 \pm 21$ & $62,4 \pm 0,10$ & $665,3 \pm 1,5$ \\
FB & 9 & 1 & 1 & $627 \pm 15$ & $61,8 \pm 0,15$ & $727,0 \pm 1,0$ \\
FC & 9 & 1 & 3 & $667 \pm 15$ & $61,5 \pm 0,15$ & $743,3 \pm 2,1$ \\
FD & 9 & 1 & 5 & $710 \pm 10$ & $61,3 \pm 0,15$ & $796,0 \pm 1,7$ \\
\hline
\end{tabular}

Table 2. Formulation of PVA-GA-honey-based nanofibers dressing

\begin{tabular}{lllll}
\hline Formula & $\begin{array}{l}\text { PVA } \\
(\% \mathbf{w} / \mathbf{v})\end{array}$ & $\begin{array}{l}\text { GA } \\
(\% / \mathbf{w})\end{array}$ & $\begin{array}{l}\text { Triton X-100 } \\
(\mathbf{\%} \text { v/v) }\end{array}$ & $\begin{array}{l}\text { Honey } \\
(\mathbf{\%} \text { w/v) }\end{array}$ \\
\hline FAt & 9 & 1 & 0,05 & 0 \\
FBt & 9 & 1 & 0,05 & 1 \\
FCt & 9 & 1 & 0,05 & 3 \\
\hline
\end{tabular}

out at room temperature with relative humidity of \pm $35 \%$. The nanofibers dressing were then dried at room temperature in the desiccator.

\section{Characterization of Nanofibers Dressing Scanning Electron Microscope (SEM)}

The surface morphology and the size of the nanofibers dressing was characterized using SEM (JEOL JSM6510LV). Prior to observation, the nanofibers were coated with gold in order to be electrically conductive. Images were obtained at excitation voltage of $15 \mathrm{kV}$. Nanofiber diameters were then calculated at 100 points from SEM images processed using ImageJ software version $1.52 \mathrm{a}$ (USA).

\section{RESULTS AND DISCUSSION}

\section{Characteristics of Blended Solution of PVA-GA- Honey Based}

The color of the FA solution was transparent while the color of the solutions of FB, FC, and FD was yellowish to brownish due to addition of honey. The physical properties of all solutions were then measured and the results is depicted in Table 1 .

The effect of honey addition with varied concentration on the viscosity, surface tension, and conductivity of the solutions FA, FB, FC, and FD can also be seen in Figure 2. Based on data from Table 1 and Figure 2, it showed that the viscosity and conductivity increased with increasing concentration of honey. Meanwhile, the surface tension of the solution was lower as the concentration of honey increased, but the difference is insignificant. The FA solution has a viscosity of 573 $\pm 21 \mathrm{mPa}$.s, while the viscosity of the solution of FB, $\mathrm{FC}$, and FD was respectively $627 \pm 15 \mathrm{mPa} . \mathrm{s} ; 667 \pm 15$
$\mathrm{mPa}$.s; and $710 \pm 10 \mathrm{mPa}$.s. The addition of honey into the solution increased the viscosity of the solution since honey is a viscous solution. Honey is a natural mixture that contains very high sugar levels, namely glucose and fructose (85-95\%) and sucrose. It also contains small amounts of amino acids, enzymes, organic acids, vitamins, minerals, and polyphenols (Maleki et al., 2012; Wong et al., 2013).

GA as an anionic hydrocolloid increased the conductivity of $9 \%$ PVA solution when the two solutions are mixed. FA solution showed conductivity value of $665.3 \pm 1.5$ $\mu \mathrm{S} / \mathrm{cm}$, while the conductivity of the solution $\mathrm{FB}, \mathrm{FC}$, and FD, were respectively, $727.0 \pm 1.0 \mu \mathrm{S} / \mathrm{cm} ; 743.3$ $\pm 2.1 \mu \mathrm{S} / \mathrm{cm}$; and $796.0 \pm 1.7 \mu \mathrm{S} / \mathrm{cm}$. This is because of the amount of ions present in the solution. The higher concentration of honey, the greater the conductivity of the solution. These results are similar with previous studies conducted by Sarhan, Azzazy, and El-Sherbiny (2016) who reported increase in the conductivity of the mixture of PVA and chitosan solution as the concentration of honey increase.

Optimization of Electrospinning Process PVA-GAHoney Based on Formula Variations.

After the results of measurements of viscosity, surface tension, and conductivity of the FA, FB, FC, and FD formulas were obtained, the blended solution was used for electrospinning process at applied voltage $20 \mathrm{KV}$; flowrate $1 \mu \mathrm{l} /$ minutes; with horizontal distance of $18 \mathrm{~cm}$ from the needle tip to the collector and relative humidity $\pm 35 \%$. There were only 3 formulas (FA, FB, and FC) which successfully spun into nanofibers dressing, while the FD solution was clogged at the needle tip during electrospinning since the solution was too viscous. Higher viscous solution causes the droplets of the 


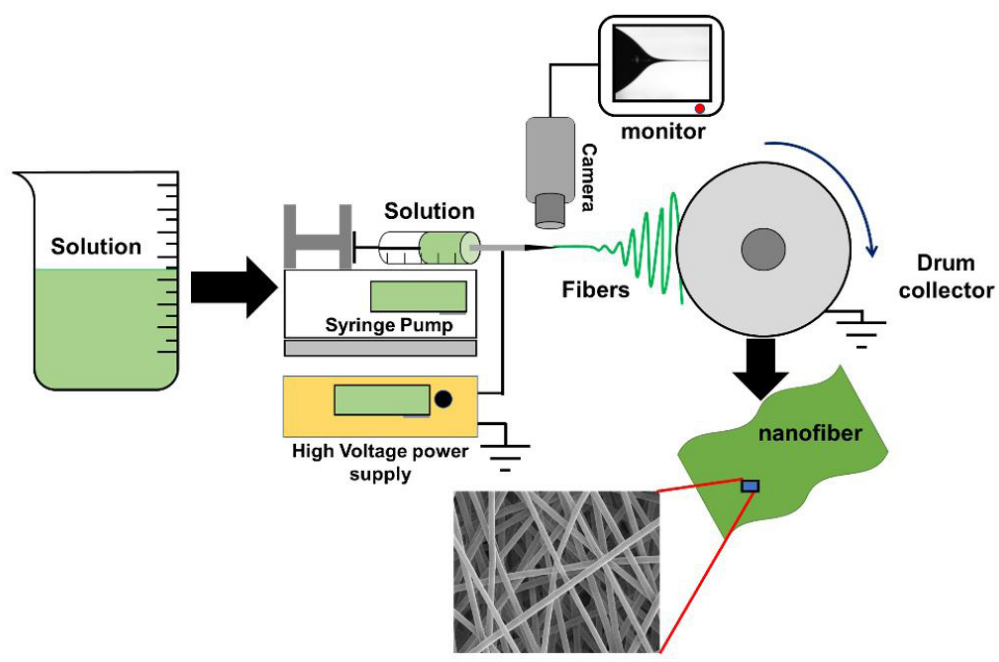

Figure 1: A diagram of the electrospinning system used for nanoscale production

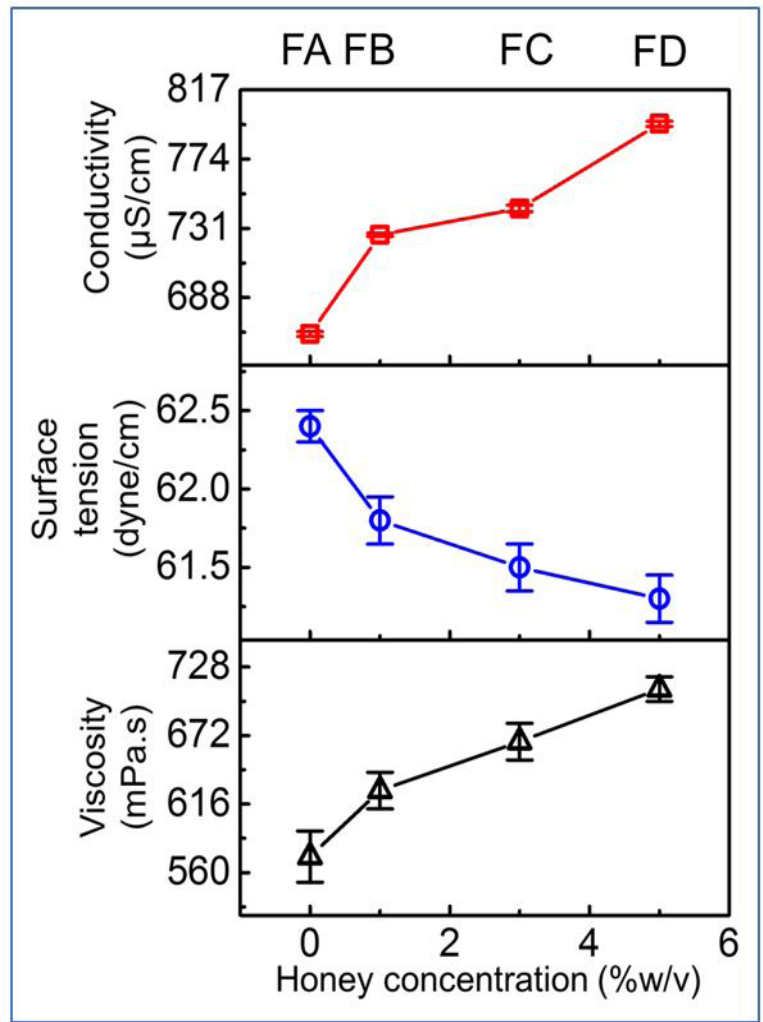

Figure 2. Effect of honey concentration on viscosity, surface tension and conductivity of the solution FA, FB, FC and, FD

solution on the tip of the needle to dry out easily during the electrospinning process because the amount of solvent to be evaporated is too small (Ramakrishna et al., 2005). Research conducted by Rezaei et al (2016) also reported the same thing, that the polymer mixture of almond gum and PVA with concentrations greater than $10 \% \mathrm{w} / \mathrm{w}$ was difficult to be spun since the solution gets clogged on the tip of the needle because of the solution was too viscous. Another study also stated that the optimum viscosity for the manufacture of PEO nano fibers is 800-4000
$\mathrm{cP}$, while the optimal viscosity for the manufacture of polyacrylonitrile (PAN) polymeric nanoparticles is 1.7215 cP (Haider et al., 2015).

The obtained nanofibers dressing were then morphologically characterized using SEM. The morphology and diameter size of the nanofibers was analysed using Image J software by selecting 100 fibers at random. The distribution curve and nanoscale diameter graph are created using origin Pro 9.0. The SEM image 


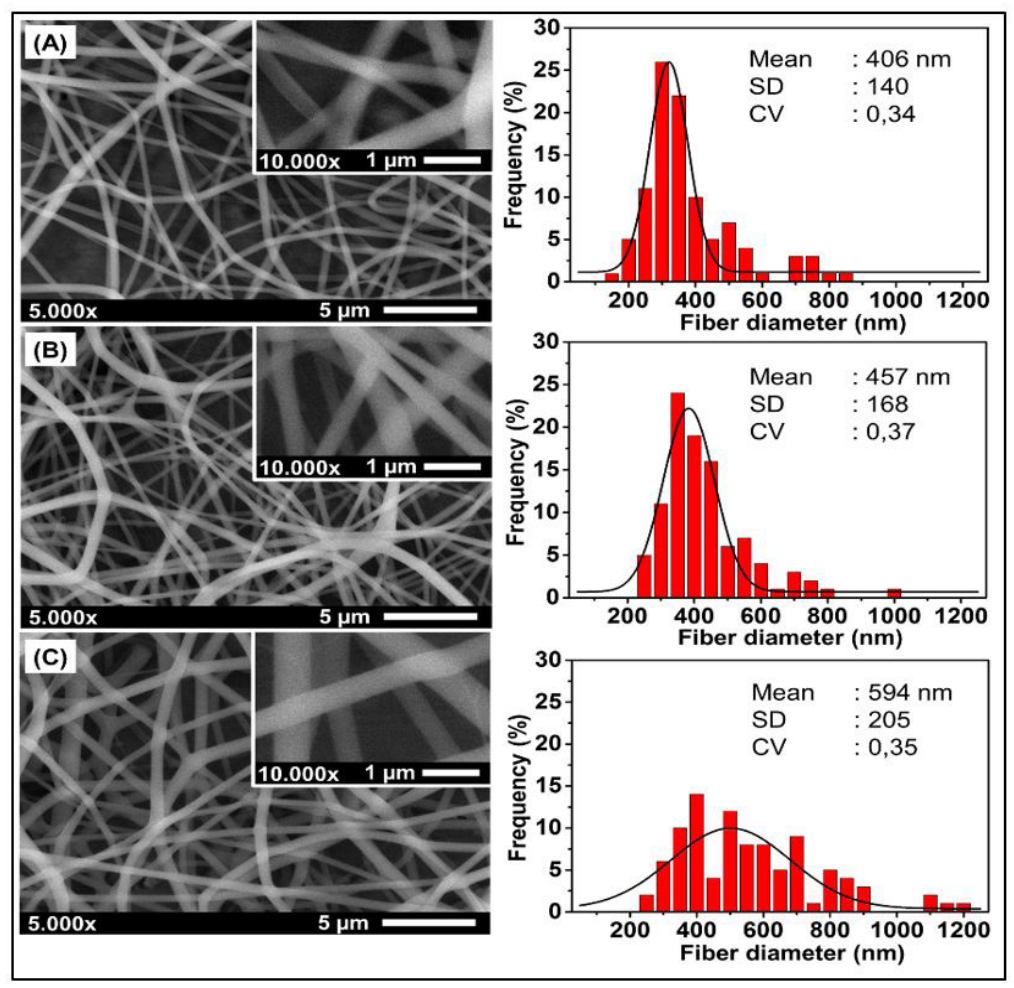

Figure 3. SEM image of 5000x and $10.000 x$ magnification and nanoscale diameter distribution curve FA, FB, and FC with a various honey concentration (A) 0 , (B) 1 , and (C) $3 \% \mathrm{~b} / \mathrm{v}$

and the nanoscale diameter distribution curve of the electrospun fibers of FA, FB, and FC are shown in Figure 3.

Figure 3 showed that the morphology of the nanofibers produced were less uniform with the average diameters in the three formulas in the range of $100 \mathrm{~nm}$ to 1200 $\mathrm{nm}$. The obtained nanofibers wereporous and distributed randomly. From the data obtained the average diameter of nanofibers in FC $(594 \pm 205 \mathrm{~nm})$ was the highest compared to FB $(457 \pm 168 \mathrm{~nm})$ and FA $(406 \pm 140 \mathrm{~nm})$. The solution FC had the highest compared to FB and FA so there was less stretch of polymer jet during the travel from the needle tip to the collector. As a result the diameter of the fibers was larger. Additionally, a solution with high viscosity can prevent the occurrence of secondary jets (jet splits), which usually can reduce the diameter of the nanofibers of causing the diameter to be non- uniform (Ramakrishna et al., 2005; Zhang et al., 2017).

The diameter of nanofibers with the range of 50-500 $\mathrm{nm}$ resembles natural extracellular matrices which can be utilized to accelerate homoestasis (Orue et al., 2017). Based on the data above, the diameter of the electrospun nanofibers for the three formulas were still above the permissible range. In addition, the diameter distribution of the nanofibers obtained was also not uniform in the three formulas based on the value of coefficient of variation, or the ratio of standard deviation over mean value, which was above 0.3 (Matulevicius et al., 2015). There are several factors that cause highly diverse size of the fiber diameter. One of the contributing factors is high surface tension. In Table 2, it was shown the surface tension data of the three formulas were high, with the value of surface tension for FA, FB, and FC were respectively, $62.4 ; 61,8 ; 61.5 \mathrm{dyne} / \mathrm{cm}$. Hence, the high surface tension caused the electrospinning process not to be able to run continuously. The high surface tension produces an unstable jet and there was a moment where the spherical solution droplets jumped from the tip of the needle directly to the collector. Therefore the electric voltage needs to be increased to overcome surface tension (Ramakrishna et al., 2005).

Characteristics of Blended Solution of PVA-GAHoney with Addition of Triton X-100

In fact the electrospinning process did not run continuously and the diameter of the obtained nanofibers were very diverse. One way to overcome this is by adding nonionic surfactant namely Triton X-100. The purpose of adding surfactant was to reduce the surface tension of the solutions. Low surface tension is highly recommended because it will reduce the critical voltage required to produce jet of the solution from the Taylor cone (Chul et al., 2009). The nanofibers formed will be more smooth and uniform with the addition of surfactants (Ramakrishna et al., 2011; Risdian et al., 


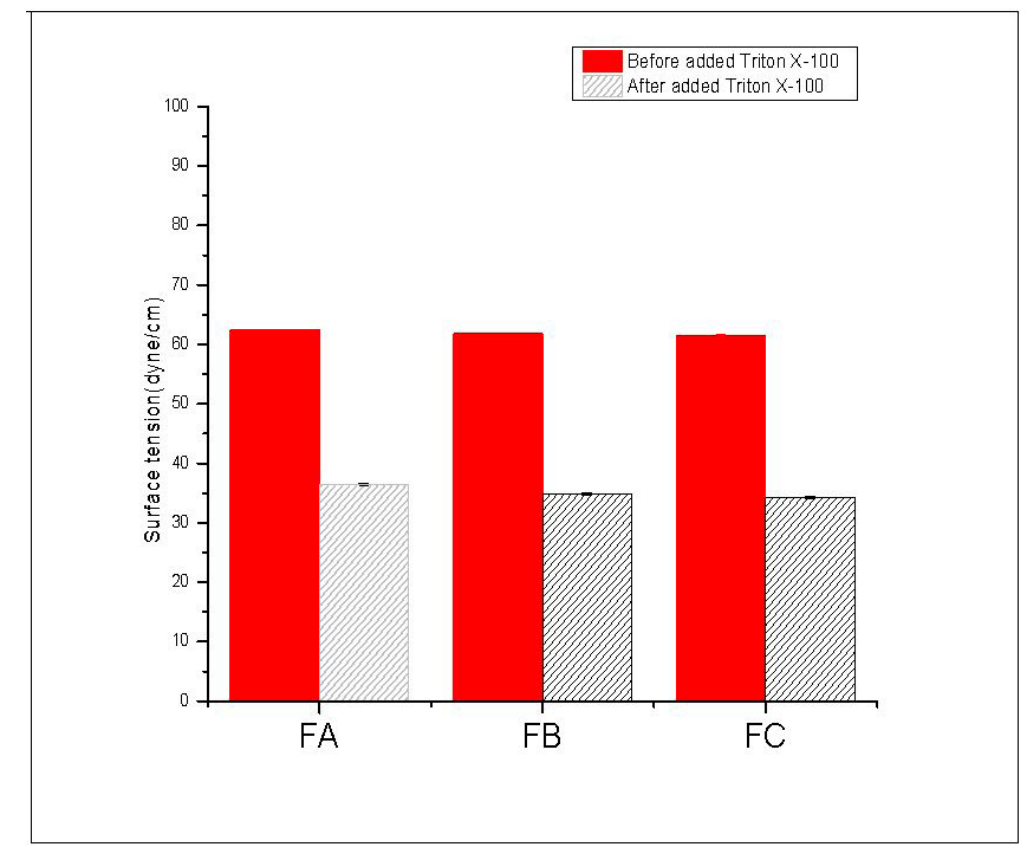

Figure 4. Surface tension of PVA-GA-Honey solution before and after addition of Triton X-100 $(0,5 \% \mathrm{v} / \mathrm{v})$

2015: Zhang et al., 2017).

PVA-GA and PVA-GA-honey solutions from the previous section was then added with Triton X-100 and then named as FAt, FBt, and FCt. The solutions were again characterized for its physical property of the solution, especially its surface tension. Based on the data in Figure 4 the surface tension in the FAt, FBt, and FCt formulas with the addition of Triton X-100 $(0.05 \% \mathrm{v} / \mathrm{v})$ decreased significantly compared to the FA, FB, and FC formulas which were respectively from 62,$4 ; 61,8 ; 61.5$ to $36.47 ; 34.83 ; 34.20$ dyne/cm respectively. Similarly, Zhang et al (2017) have reported that the addition of $1 \% \mathrm{w} / \mathrm{w}$ Tween 80 into $25 \% \mathrm{w} / \mathrm{v}$ gelatin solution can significantly reduce the surface tension from $37.86 \pm 0$, 04 to $19.76 \pm 0.03 \mathrm{mN} / \mathrm{m}$. The research conducted by Ziani et al (2011) reported that the addition of $40 \mathrm{mg}$ Tween 20 into chitosan-solution polyethylene oxide can reduce surface tension significantly from 52.4 to 38.8 $\mathrm{mN} / \mathrm{m}$. The addition of surfactants to polymer solutions can modulate the interaction of polymers with solvents and polymers with surfactan through electrostatic, hydrophobic, and hydrogen bond interactions (Zhang et al., 2017).

\section{Effects of Variation of Applied Voltage on Morphology and Diameter of FCt Nanofibers}

Besides the solution parameters, the success in electrospinning is also determined by process parameters. Therefore, it is necessary to optimize the process parameters, including the applied voltage and flow rate. FCt was used in this optimization due to its highest viscosity. After the most optimum process parameters had been obtained, the electrospun nanofibers were again prepared using the obtained optimized process parameters for all three solution formulas. The obtained nanofibers from the three formulas (Fat, FBt and FCt) possessed a smooth, uniform and beads-free morphology and nanoscale diameter.

The applied voltage used for the optimization were varied at 16,18 , and $20 \mathrm{KV}$, while other process parameters remained unchanged. The morphology of the nanofibers was characterized using SEM and the average diameter was calculated. The results of SEM image and the distribution diameter of nanofibers can be seen in Figure 5. It was shown that average diameters of the nanofibers reduced with increasing applied voltage. The average diameters of the nanofibers at a voltage 20 $\mathrm{kV}$ was smaller compared to nanofibers at $16 \mathrm{kV}$ and $18 \mathrm{kV}$. The diameter size of the FCt nanofibers obtained with the applied voltages of 16; 18; and $20 \mathrm{KV}$ were 333 $\pm 93 \mathrm{~nm} ; 283 \pm 57 \mathrm{~nm}$; and $242 \pm 39 \mathrm{~nm}$ respectively. At higher voltage, the higher electrical force causes larger stretching of the solution jet hence the diameter of the fibers becomes smaller. However, for applied voltage larger than $20 \mathrm{KV}$, beads occurred along the fibers since the very high voltage caused jump of jet so the time needed to stretch and vaporize the polymer chain entanglement in the solution was reduced (Ramakrishna et al., 2005). Meanwhile, at lower voltage, the diameter of the fibers increased since the amount of stretching was less. Based on these results, the optimum voltage that can be used to produce the best nanofibers was $18 \mathrm{KV}$. 


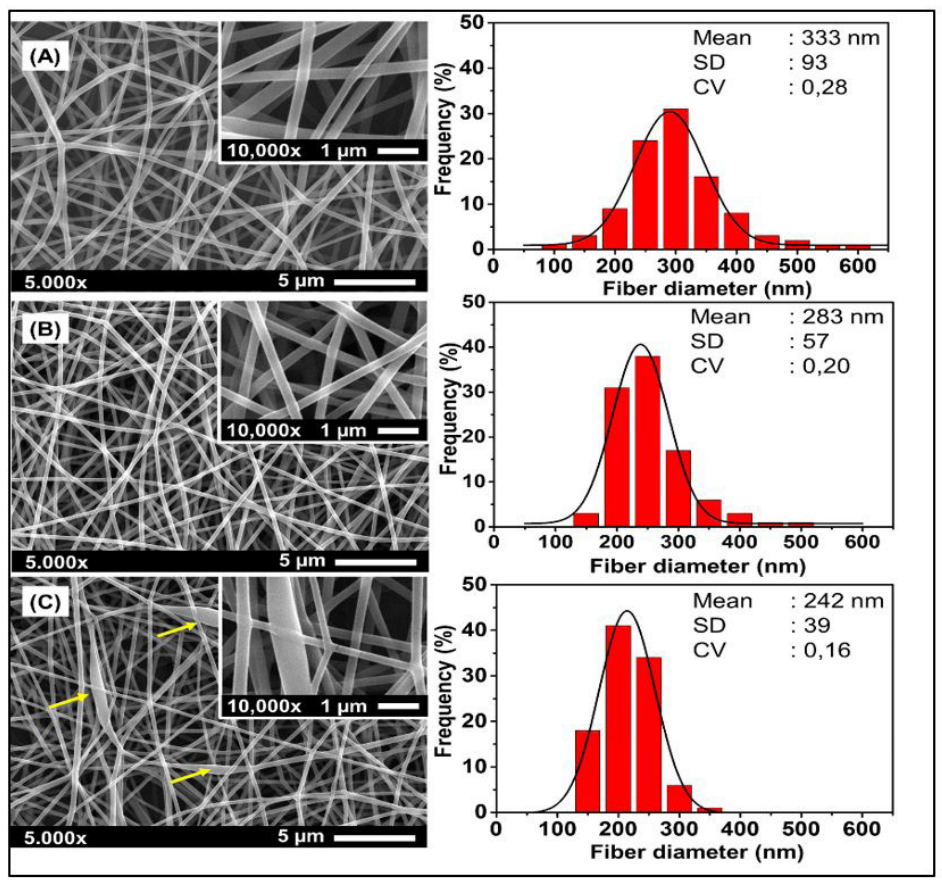

Figure 5. SEM image and the diameter distribution curve of FCt nanofibers with a various electrical voltage (A) 16, (B) 18, and (C) $20 \mathrm{kV}$ magnification of $5000 \mathrm{x}$ and $10.000 \mathrm{x}$

Effect of Varying Flow rate on Morphology and Diameter of FCt Nanofibers

The flow rate of the electrospinning process was also optimized to obtain the best and uniform fibers. The flow rates varied in this optimization were 5,8 , and 10 $\mu 1 /$ minutes, while other process parameters remained unchanged. The fibers were characterized using SEM to calculate the average diameter of each sample. The results of SEM image and the distribution of the diameter of fibers can be seen in Figure 6. Based on Figure 6, it can be shown that at higher flow rate caused larger diameter of fibers. The use of a flow rate at 5 $\mu 1 /$ minutes produced smooth and uniforms nanofibers without beads. As the flow rate of the solution got larger, beads started to occur. The volume of the droplets at the tip of the needle increased at higher flow rate and caused the elongation process of the polymer chain became imperfect. Additionally, the increase of the flow rate causes the evaporation process did not fully dry up the solvent as the volume of jet is large. Hence the fibers arrived at the collector is still wet. (Ramakrishna et al., 2005).

Effect of Various Formulas with addition Triton X-100 on Morphology and Diameter of Nanofibers using Optimum Electric Voltage and Flow rate.

The nanofibers morphology of the three formulas were observed using a scanning electron microscope (SEM). The results of this morphological observation is shown in Figure 7. The addition of Triton x-100 into all three FAt, FBt, and FCt formulas improved the morphology and diameter size of nano fibers produced compared to the previous formula without Triton $X-100$. The morphology of obtained electrospun nanofibers was smooth, randomly oriented and uniform as indicated by the coefficient of variation to be below 0.3 . Based on the results of research by Risdian et al (2015), the presence of Triton X-100 at concentration $0.05 \% \mathrm{v} / \mathrm{v}$ can affect the morphology of the nanofibers produced. The addition of a small amount of non-ionic surfactant to the polymer solution decreases the surface tension of the solution so that it can increase the electrospinnability of the solution and increase its reproducibility during the electrospinning process (Ziani et al., 2011). A similar study also stated that the addition of non-ionic surfactants (Tween 20) to chitosan-polyethylene oxide solutions could improve the ability of the solution to be electrically spun. The nanofibers has better morphology with added surfactant compared to the fibers produced from blended solution without the addition of Tween 20 (Ziani et al., 2011). According to Bertoncelj. V et al (2014), the morphology and size of the diameter of nanofibers affect the cell proliferation process. The process of cell proliferation invitro decreases if there is a defect/bead in nanofibers. The diameter of nanofibers at range 50-500nm resembles natural extracellular matrices which can accelerate the process of homoestasis in wounds (Orue et al., 2017). From the data obtained the average diameter of nanofibers produced from FCt, FBt, and FAt was $283 \pm 57 \mathrm{~nm} ; 266 \pm 45 \mathrm{~nm}$; and $244 \pm 45$ $\mathrm{nm}$, respectively. The large diameter of FCt was due to its highest viscosity. The nanofibers diameter increased with increasing viscosity of solution (Ramakrishna et al., 


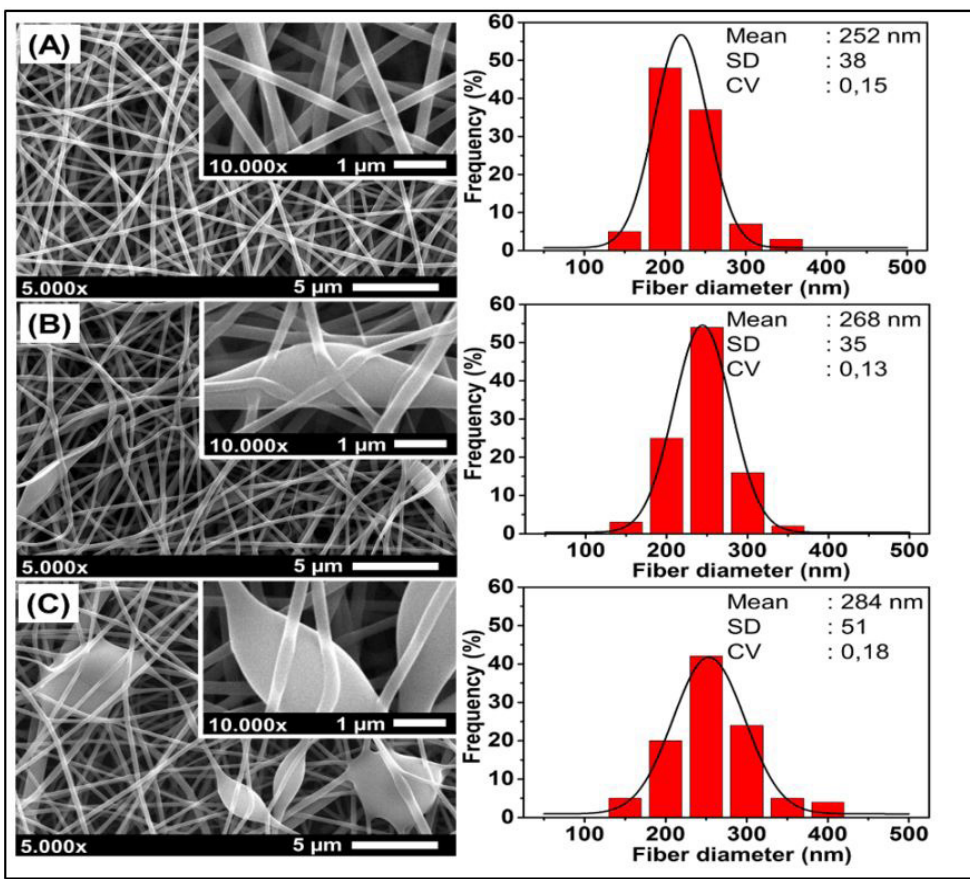

Figure 6 . SEM image and the diameter distribution curve of FCt nanofibers with a various flow rate (A) 5, (B) 8, and (C) $10 \mu \mathrm{l} /$ minutes magnification of $5000 \mathrm{x}$ and $10.000 \mathrm{x}$
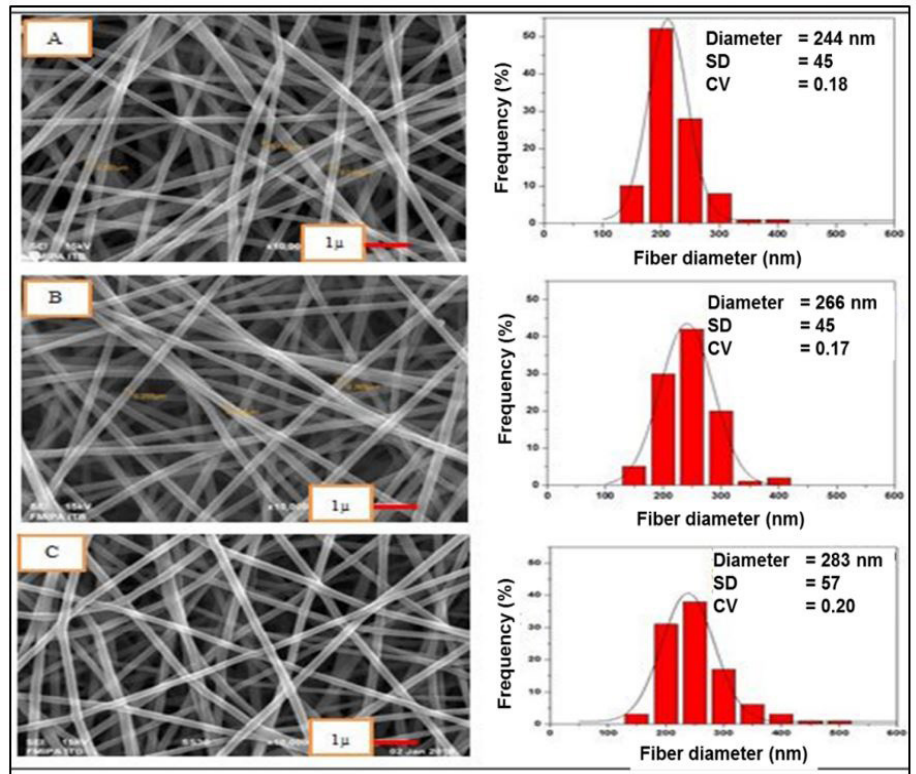

Figure 7. SEM image and the diameter distribution curve of nanofibers with a various formulas (A) FAt, (B) FBt, and (C) FCt magnification of $10.000 \mathrm{x}$

2005). From the data, it is shown that the morphology and diameter size of the obtained nanofibers were within the range of the size of the natural extracellular matrix.

\section{CONCLUSION}

PVA-GA-honey-based nanofibers have been successfully optimized with good morphology, smooth surface and uniform diameter in nanoscale which is mimics the natural extracellular matrix. The most optimum process parameters for produce fibers was the applied voltage and flow rate at $18 \mathrm{KV}$ and $5 \mu \mathrm{l} /$ minutes. The result showed that FCt (with $3 \%$ of honey and $0.05 \%$ of Triton $\mathrm{X}-100)$ was the best formula with the average fibers diameter of FCt obtained $283 \pm 57 \mathrm{~nm}$ that still within the range of the extra cellular matrix. Additionally, at higher honey content in FCt, the wound healing process could accelerated and protected the stability of growth 
factors during the electrospinning process. Furthermore FCt have the potential to be further developed as carrier for peptide and protein drugs.

\section{ACKNOWLEDGMENT}

The authors gratefully acknowledge the research grant support from The Ministry of Research, Technology, and Higher Education, Republic of Indonesia.

\section{REFERENCES}

Asli, M.M \& Loboa, E.G. (2016). "Nanofibrous smart bandages for wound care", Magnus S.Agren (Ed). Wound Healing Biomaterials, Vol 2: Functional Biomaterials, Pages: 485, 488

Bertoncelj, V., Pelipenko, J., Kristl, J., Jeras, M., Cukjati, M., Kocbek, P. (2014). Development and bioevaluation of nanofibers with blood-derived growth factors for dermal wound healing. European Journal of Pharmaceutics and Biopharmaceutics, 88 (2014) 64-74

Bhatnagar, M., Parwani, L., Sharma, V., Gaungli, J., Bhatnagar, A. (2013). Hemostatic, antibacterial biopolymers from Acacia arabica (Lam.) Wild. And Moringa oleifera (Lam.) as potential wound dressing. Indian Journal of Experimental Biology, 51, 804-810

Felgueiras, P.H \& Amorim, P.T.M. (2017). Functionalization of electrospun polymeric wound dressing with antimicrobial peptides. Colloids and Surfaces B:Biointerfaces. 156, 133-148

Haider, A., Haider, S., Kang, I.K. (2015). A comprehensive review summarizing the effect of electrospinning parameters and potential applications of nanofibers in biomedical and biotechnology. Arabian Journal of Chemistry, (2018) 11, 1165-1188. .

Maleki, H., Gharehaghaji, A.A., Dijkstra, P.J. (2012). A novel honey-based nanofibrous scaffold for wound dressing application. Journal of Applied Polymer Science.

Matulevicius, J., Kliucininkas, L., Prasauskas, T., Buivydiene, D, Martuzevicius, D. (2016). The comparative study of aerosol filtration by electrospun polyamide, polyvinyl acetate, polyacrylonitrile and cellulose acetate nanofiber media. Journal of Aerosol Science, 92, 27-37

Orue, I.G., Pedraz, J.L., Hernandez, R.M.,Igartua, M. (2017). Nanotechnology-based delivery system to release growth factors and other endogenous molecules for chronic wound healing. Journal of Drug Delivery

\section{Science and Technology, 42, 2 - 17}

Orue, I.J., Gainza, G., Gutierrez, F.B., Aguirre, J.J., Evora, C., Pedraz, J.L., Hernandez, R.M.., Delgado, A., Igartua, M. (2017). Novel nanofibrous dressing containing rhEGF and Aloe vera for wound healing applications. International Journal of Pharmaceutics, 523, 556-566.

Oryan, A., Alemzadeh, E., Moshiri, A. (2016). Biological properties and theraupetic activities of honey in wound healing: A narrative review and meta-analysis. Journal of Tissue Viability, 25, 98-118

Park, Hwang, \& Yoon. (2017). Advanced Growth Factor Delivery System in Wound Management and Skin Regeneration.Molecules Review, 22, 1259

Ramakrishna.S., Fujihara,K., Teo,W.E., Lim, T.C., \& Ma, Z. (2005). An Introduction to Electrospinning and Nanofibers, World Scientific Publishing, Singapore, Pages: 106-113

Rezaei, A., Tavanai, H., Nasirpour, A. (2016). Fabrication of electrospun almond gum/PVA nanofibers as a thermostable delivery system for vanillin. International Journal of Biological Macromolecules, 536-543

Risdian, C., Nasir,M., Rahma,A., \& Rachmawati,H. (2015). The influence of formula and process on physical properties and the release profile of PVA/ BSA nanofibers formed by electrospinning technique. Journal of Nano Research, Vol.31,103-116

Sarhan, A., Azzazy, H., Sherbiny, I. (2016). The effect of increasing honey concentration on the properties of the honey/polyvinyl alcohol/chitosan nanofibers. Material Science and Engineering C, 67, 276-284

Wang, J \& Windbergs, M. (2017). Functional electrospun fibers for the treatment of human skin wounds. European Journal of Pharmaceutics and Biopharmaceutics. 119, 283-299

Wong, Y.H., Kadir, H.A., \& Tayyab. (2013). Honeyinduced protein stabilization as studied by fluorescein isothiocyanate fluorescence. Scientific World Journal. https://doi.org/ 10.1155/2013/981902

Zhang, Q., Li, Y., Yuan, Z., Wong, K.Y., Lin, M., Yildirimer, L., \& Zhao, X. (2017). Electrospun polymeric micro/nanofibrous scaffolds for long-term drug release and their biomedical applications. Drug Discovery Today, 22(9), 1351-1366

Zhang, H., Feng, F. , Liu, Y., Kang, X., \& Deng, L. (2017). Effects of surfactants on the formation of gelatin 
nanofibres for controlled release of curcumin. Food Chemistry, 231, 70-77

Ziani, K., Henrist, C., Jerome, C., Aqil, A., Mate, JI, \& Cloots, R, (2011). Effect of nonionic surfactant and acidity on chitosan nanofibers with different molecular weights. Carbohydrate Polymers, 83, 470-476 